J Arid Land (2013) 5(3): 384-395

doi: $10.1007 / \mathrm{s} 40333-013-0169-8$

jal.xjegi.com; www.springer.com/40333

\title{
Estimation of water balance in the source region of the Yellow River based on GRACE satellite data
}

\author{
Min $\mathrm{XU}^{1,2}$, BaiSheng $\mathrm{YE}^{1,2}$, QiuDong ZHAO ${ }^{2}$, ShiQing ZHANG ${ }^{2 *}$, Jiang WANG ${ }^{2}$ \\ ${ }^{1}$ State Key Laboratory of Cryospheric Science, Cold and Arid Regions Environmental and Engineering Research Institute, Chinese \\ Academy of Sciences, Lanzhou 730000, China; \\ ${ }^{2}$ Cold and Arid Regions Environmental and Engineering Research Institute, Chinese Academy of Sciences, Lanzhou 730000, China
}

\begin{abstract}
Water storage has important significance for understanding water cycles of global and local domains and for monitoring climate and environmental changes. As a key variable in hydrology, water storage change represents the sum of precipitation, evaporation, surface runoff, soil water and groundwater exchanges. Water storage change data during the period of 2003-2008 for the source region of the Yellow River were collected from Gravity Recovery and Climate Experiment (GRACE) satellite data. The monthly actual evaporation was estimated according to the water balance equation. The simulated actual evaporation was significantly consistent and correlative with not only the observed pan $(20 \mathrm{~cm})$ data, but also the simulated results of the version 2 of Simple Biosphere model. The average annual evaporation of the Tangnaihai Basin was $506.4 \mathrm{~mm}$, where evaporation in spring, summer, autumn and winter was $130.9 \mathrm{~mm}, 275.2 \mathrm{~mm}, 74.3 \mathrm{~mm}$ and $26.1 \mathrm{~mm}$, and accounted for $25.8 \%$, $54.3 \%, 14.7 \%$ and $5.2 \%$ of the average annual evaporation, respectively. The precipitation increased slightly and the actual evaporation showed an obvious decrease. The water storage change of the source region of the Yellow River displayed an increase of $0.51 \mathrm{~mm}$ per month from 2003 to 2008 , which indicated that the storage capacity has significantly increased, probably caused by the degradation of permafrost and the increase of the thickness of active layers. The decline of actual evaporation and the increase of water storage capacity resulted in the increase of river runoff.
\end{abstract}

Keywords: actual evaporation; GRACE satellite data; water storage change; water balance equation; source region of the Yellow River

Citation: Min XU, BaiSheng YE, QiuDong ZHAO, ShiQing ZHANG, Jiang WANG. 2013. Estimation of water balance in the source region of the Yellow River based on GRACE satellite data. Journal of Arid Land, 5(3): 384-395.

The Tibetan Plateau (TP) is the highest plateau in the world. It has an average elevation of $4,000 \mathrm{~m}$ above sea level and covers an area of about $2.5 \times 10^{6} \mathrm{~km}^{2}$. The exchanges of energy and water between the land surface and atmosphere over the TP play an important role in the changes of regional climate and water resources.

Evaporation is a major component of the surface energy balance and water balance, and is a key connection between the soil and the atmosphere in the hydrological cycle, which plays an important role in the assessment of climate change (Milly and Shmakin,
2002; Döll et al., 2003; Wang et al., 2005). The source region of the Yellow River is part of TP. The study on actual evaporation and water storage change will improve our understanding of the water cycle and provide hydrological information to facilitate water resource management in the source region of the Yellow River. However, only the potential evaporation can be measured at site scale, and it is difficult to directly measure the actual evaporation in a watershed; thus, the estimation of evaporation has been a research priority in hydrological science. The methods used to estimate actual evaporation can, at present, be divided

*Corresponding author: ShiQiang ZHANG (E-mail: xumin@126.com)

Received 2013-01-09; revised 2013-02-06; accepted 2012-03-11

(C) Xinjiang Institute of Ecology and Geography, Chinese Academy of Sciences, Science Press and Springer-Verlag Berlin Heidelberg 2013 
into two main ones: one based on hydrology and meteorology, the other derived from remote sensing data. For the water balance method (hydrology and meteorology), meteorological station observations of pan evaporation $\left(\mathrm{ET}_{\mathrm{pan}}\right)$ are all included (Wang et al., 2006, 2010; Wu et al., 2006). Model calculation of evaporation is more common, and more accurate results can be obtained by observations under allowable climate conditions. It is difficult to obtain actual evaporation from observation data of meteorological stations due to limited observation methods. In addition, site evaporation observation data are usually obtained by this method, and simulated evaporation probably contains large errors due to the limited stations in a watershed. Generally, the observed evaporation only provides clues to understanding the changing patterns of evaporation, but ultimately, the important issue in water balance is land-surface actual evaporation $\left(\mathrm{ET}_{\mathrm{a}}\right)$ (Rodell et al., 2004; Ohmura and Wild, 2008).

The water balance method does not consider the impact of atmospheric motion in detail, and is a relatively simple and widely accepted method of calculating the actual evaporation of a watershed. However, a highly accurate measure of water storage change within a watershed is difficult by using the water balance equation. The water storage change of a watershed is assumed to be zero over a certain time period (one year or multi-year). Thus, it is difficult to calculate the actual evaporation on monthly or smaller scale by the water balance equation. Water storage has important significance for understanding the water cycle of global and local domains and for monitoring climate and environmental changes. As a key variable in hydrology, water storage change represents the sum of precipitation, evaporation, surface runoff, soil water and groundwater exchanges (Zhong et al., 2009). The satellite can obtain high precision and high time resolution data of spatial and temporal variations of the gravity field of the Earth by month, which can be used to retrieve water storage change (Wahr and Swenson, 1998). The United States National Aeronautics and Space Administration (NASA) and Germany's Aerospace Center launched the Gravity Recovery and Climate Experiment (GRACE) satellite in March 2002. GRACE can detect the terrestrial water storage changes within as small as $1 \mathrm{~cm}$, and its spatial resolution is $1^{\circ} \times 1^{\circ}$ (Wahr and Swenson, 2004). The water storage change can be retrieved from the GRACE satellite data, following which month-scaled evaporation of a watershed can be calculated by the water balance equation.

In recent years, scholars have researched the seasonal water storage change of many watersheds around the world using GRACE data. Tapley et al. (2004a) used GRACE data to research water storage in South America. This research demonstrated the high precision gravity data provided by GRACE and the usefulness of the data for research of large scale hydrological processes. Ramillien et al. (2004) pointed out that GRACE can detect the micro-distribution of water on the Earth in a short time and has a high precision by which water storage change within as small as $1.0-1.5 \mathrm{~cm}$ can be estimated. Velicogna et al. (2006) studied water storage changes in the Mississippi River basin, the Amazon River basin and Ganges River basin using GRACE time-variable gravity data of 11 months, and they found that the precision of GRACE storage data can reach higher than $1.0-1.5 \mathrm{~cm}$. Hu et al. (2006) revealed marked seasonal changes of water storage across the world from April 2002 to December 2003, a total of 15 months. Their study emphasized the changes in water storage in the Yangtze River basin in China, with the maximum storage occurring during spring and early autumn. Yang et al. (2009) analyzed seasonal and inter-annual water storage change of 27 watersheds worldwide during 2003-2007. In their study, GRACE and Global Land Data Assimilation System (GLDAS) data indicated that after 2006, the inter-annual variability of land water storage showed obvious increases. Zhong et al. (2009) used GRACE gravity satellite data of nearly 5 years to study the long-term trends of terrestrial water storage variations in China. GRACE data enhanced our understanding of the water cycle, thereby allowing better prediction of the global climate, actual evaporation process of water resources, drought and land surface changes.

In this paper, water storage change was calculated using GRACE time-variable gravity field data during the period of 2003-2008. An analysis of spatio-temporal water storage change as well as precipitation and 
runoff change in the source region of the Yellow River was analyzed. Then, the actual evaporation in the study area was calculated according to the water balance equation, and the result was compared with that of simulations of the $\mathrm{SiB} 2$ model and $\mathrm{ET}_{\text {pan }}$ data from national meteorological stations.

\section{Data and methods}

\subsection{Study area}

The source region of the Yellow River located above the Tangnaihai station $\left(110.15^{\circ} \mathrm{E}, 35.5^{\circ} \mathrm{N}\right)$ and in the northeastern Qinghai-Tibet Plateau (Fig. 1) was selected as the study area. The area of the basin is $1.22 \times 10^{5} \mathrm{~km}^{2}$, accounting for $16 \%$ of the total Yellow River basin area. The basin surface is covered by seasonal frozen soil and permafrost. This area is the largest ice and snow melting area of Yellow River and one of the primary runoff formation zones.

\subsection{Hydro-meteorological data} In this study, the data from only eight national mete-

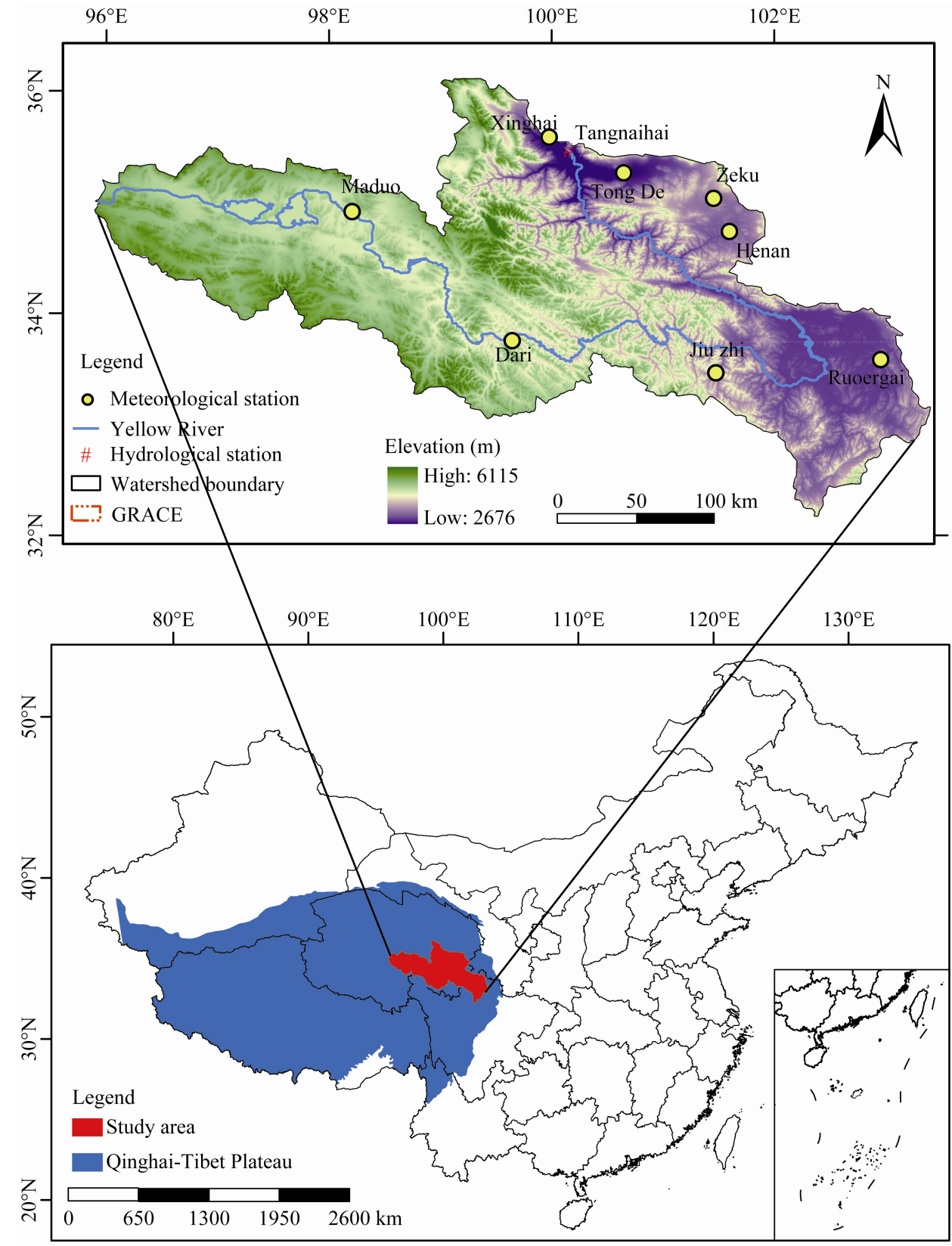

Fig. 1 The position of the source region of the Yellow River 
orological stations in the source region of the Yellow River (Table 1) during the period of 2003-2008 were available because of the scarcity of national meteorological stations in this area. An additional 40 national meteorological stations around the study area were selected to improve the accuracy of interpolation. Monthly precipitation and temperature data were collected by Ding et al. (2007), following which monthly precipitation and pan evaporation data of 48 national meteorological stations were interpolated by Kriging considering elevation, Inverse Distance Weight (IDW), Ordinary Kriging (OK) and Spline (Xu et al., 2012). Temperature data were interpolated by IDW. We obtained spatial precipitation and pan evaporation data of the basin, however, pan evaporation data were missing for July, August and September of 2005. Monthly runoff data during the period of 2003-2008 were selected from Tangnaihai hydrological station (Fig. 1).

Table 1 Meteorological stations located within the source region of the Yellow River

\begin{tabular}{ccc}
\hline Station & Longitude & Latitude \\
\hline Maduo & $98.21^{\circ} \mathrm{E}$ & $34.91^{\circ} \mathrm{N}$ \\
Dari & $99.65^{\circ} \mathrm{E}$ & $33.75^{\circ} \mathrm{N}$ \\
Xinghai & $99.98^{\circ} \mathrm{E}$ & $35.58^{\circ} \mathrm{N}$ \\
Tongde & $100.65^{\circ} \mathrm{E}$ & $35.26^{\circ} \mathrm{N}$ \\
Zeku & $101.46^{\circ} \mathrm{E}$ & $35.03^{\circ} \mathrm{N}$ \\
Jiuzhi & $101.48^{\circ} \mathrm{E}$ & $33.46^{\circ} \mathrm{N}$ \\
Henan & $101.60^{\circ} \mathrm{E}$ & $34.73^{\circ} \mathrm{N}$ \\
Ruoergai & $102.96^{\circ} \mathrm{E}$ & $33.58^{\circ} \mathrm{N}$ \\
\hline
\end{tabular}

\subsection{Retrieval method of water storage change data}

The joint US-German (NASA-GFZ) Gravity Recovery and Climate Experiment (GRACE) provides nominal monthly near-surface water storage equivalent changes. The tandem satellites measure variations in gravity indirectly through changes of the inter-satellite range and range rate from an initial orbit altitude of $485 \mathrm{~km}$. The gravitational field of the Earth can be described as geoids.

In this study, we used the Release-04 (R4) Level-3 grids provided by the GRACE Science Team centers. The global grids are 1-arc-degree water equivalent mass change complete to degree and order 60 (ftp:// podaac.jpl.nasa.gov/pub/tellus/monthly_mass_grids/).
The GRACE solution to the gravity potential formulated as an equivalent water mass change (length scale) is given by:

$$
\begin{gathered}
\Delta h(\phi, \lambda, t)=\frac{a_{e} \rho_{e}}{3 \rho_{w}} \sum_{l=0}^{40} \sum_{m=0}^{l} \frac{(2 l+1)}{1+k_{l}} W_{l} P_{l m} \sin (\phi) \\
{\left[\Delta C_{l m}(t) \cos (m \lambda)+\Delta S_{l m}(t) \sin (m \lambda)\right],} \\
W_{l}=\exp \left[\frac{\left(l r / a_{e}\right)^{2}}{4 \ln (2)}\right] .
\end{gathered}
$$

Where, $\mathrm{P}_{\mathrm{lm}}$ are normalized legendre polynomials; $\Delta \mathrm{C}_{\mathrm{lm}}(\mathrm{t})$ and $\Delta \mathrm{S}_{\mathrm{lm}}(\mathrm{t})$ are normalized time-varying stokes spherical harmonic geo-potential coefficients; $a_{e}$ is the Earth mean radius; $r$ is the spatial radius; $k_{l}$ are love numbers; $\rho_{\mathrm{e}}$ is the Earth's mean density; $\rho_{\mathrm{w}}$ is water density; $\mathrm{t}$ is time; and $\phi, \lambda$ are latitude and longitude, respectively (Ramillien et al., 2004; Tapley et al., 2004b).

The GRACE R4 Level-3 (300 km smoothing kernel) land and ocean monthly grids from 2003 to 2008 were combined to give global coverage (Hu et al., 2006; Yang et al., 2009). Glacial isostatic adjustment (GIA) or solid mass flow within the Earth's mantle following the decay of the Pleistocene Laurentide and Cordilleran ice sheets in North America and Euro-Scandinavia were applied to the GRACE grids (Velicogna and Wahr, 2006).

\subsection{Method of calculating monthly evaporation}

The basic elements of a basinal water cycle include precipitation, runoff, evaporation and water storage change. In a closed area, various elements of the water cycle changes decide the regional water cycle characteristics. The water balance equation was used to calculate actual evaporation. The basic equation of water balance is:

$$
E T_{a}=P-R \pm \Delta W .
$$

Where, $\mathrm{ET}_{\mathrm{a}}$ is actual evaporation; $\mathrm{P}$ is precipitation; $\mathrm{R}$ is runoff; and $\Delta \mathrm{W}$ is water storage change of the watershed.

Precipitation and runoff data combined with the monthly basin water storage change of the watershed data provided by GRACE satellite data were used to calculate monthly actual evaporation according to Eq. 2.

\subsection{Actual evaporation simulated by SiB2}

To facilitate comparative analysis of estimated evapo- 
ration results for the basin, the actual evaporation simulated by $\mathrm{SiB} 2$ model was compared and have been proven with higher performance on the Qinghai-Tibet Plateau (Yang et al., 2009, 2011). In the simulation, soil and vegetation parameters which were used in the model were from the International Satellite Land Surface Climatology Project Initiative II (ISLSCL II). The resolution of these data was $1^{\circ} \times 1^{\circ}$. The vegetation data used were MODIS leaf area indices which were the product of the synthesis of 8 days where the resolution was $0.25^{\circ} \times 0.25^{\circ}$. The actual evaporation at seven sites was simulated except for that at Jiuzhi station (Fig. 1, Table 1). Because national meteorological stations are scarce in the source region of the Yellow River, evaporation of watershed was represented by the average of the seven stations.

\subsection{Method of processing water storage change}

The distribution of the GRACE grid is shown in Fig. 1, and accounts for only part of the GRACE grid at the edge of the study area; the area from the intersection of the GRACE grid cell and the watershed area were estimated. This intersection area represents the amount of watershed area within the GRACE grid cell. This was related to the amount of weight given to the watershed area to mask the GRACE grids. Equation 3 was used to assign the weight and estimate the GRACE value for the area (Haile et al., 2011):

$$
\begin{aligned}
& W_{i}=\frac{a_{i}}{g_{i}}, \\
& V_{N}=\frac{\sum_{i=1}^{n}\left(v_{i} \times w_{i}\right)}{A} .
\end{aligned}
$$

Where, $\mathrm{W}_{\mathrm{i}}$ is the weight of grid $\mathrm{i} ; \mathrm{a}_{\mathrm{i}}$ is the area of the watershed in the grid $i$ with the GRACE data grid; $g_{i}$ is area of $10 \times 10$ GRACE grid cell; $V_{N}$ is the value of data of month $\mathrm{N}$ for the entire watershed; $\mathrm{v}_{\mathrm{i}}$ is the value the data of grid $\mathrm{i}$; $\mathrm{A}$ is the total area of the watershed; and $\mathrm{n}$ is the number of the GRACE grids.

\section{Water balance components analysis}

\subsection{Water storage change in the watershed}

In this study, the RL4.1 gravity field model which was provided by CSR was used to calculate water storage change from GRACE data. The spatial distribution of water storage change accumulation during the period of 2003-2008 in the source region of the Yellow River increased from the northwest with a maximum of $149.2 \mathrm{~mm}$ to the southeast with a minimum of -31.7 mm (Fig. 2a). The spatial pattern of water storage change accumulation indicates that the water storage has increased in the northwest while has decreased in the southeast of the source region of the Yellow River. The water storage change accumulation of the source region of the Yellow River was approximately $1.46 \times 10^{9} \mathrm{~m}^{3}$ during $2003-2008$, which shows the total water storage change accumulation had increased. The spatial distribution of water storage accumulation was opposite to that of annual precipitation and consisted with the distribution of permafrost (Fig. 2), which implies that precipitation did not drive the distribution of water storage changes in this area. Rather, it is influenced by distribution of permafrost. Temperature increase (Fig. 2) led to permafrost melt and water storage increase.

The seasonal variations of water storage change during the period of 2003-2008 in the source region of the Yellow River were calculated (Fig. 3). The spatial distributions of water storage change accumulation in spring suggest that water storage increased from the southern part with $-22.6 \mathrm{~mm}$ to the northern part of the region with $35.4 \mathrm{~mm}$ during the period of 2003-2008 (Fig. 3a). The water storage change was more pronounced around the Tangnaihai hydrological station. The spatial distribution of water storage change accumulation in summer was positive in the source region of the Yellow River, with the maximum being particularly apparent in the southeast which was up to $97.5 \mathrm{~mm}$. This is mainly due to the more precipitation in this area. The water storage change has shown an increasing trend during autumn. The increased trend in the northwest is clearly more prominent than that in the center and southeast area. This is because the northwestern area enters a period of snowing during autumn, which subsequently leads to water storage increase more rapidly. During winter, the water storage in the west showed a minor increase, and in the southwest showed a negative decrease. The minimum value appeared in winter. This is because precipitation and snowfall are less during winter. 

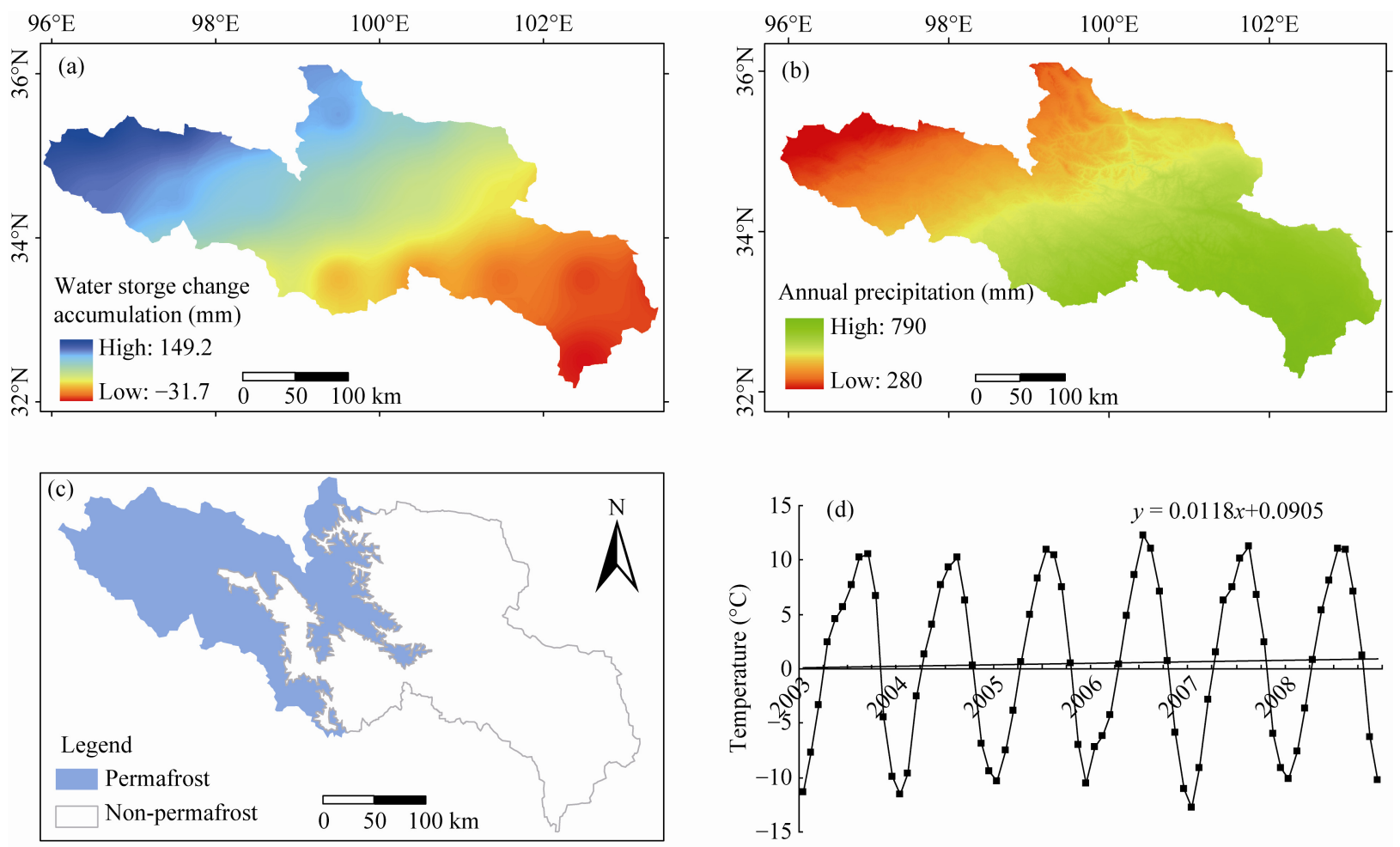

Fig. 2 The water storage change accumulation (a), annual precipitation (b), distribution of permafrost (c) and temperature (d) at the Tangnaihai station of the upper Yellow River basin during 2003-2008
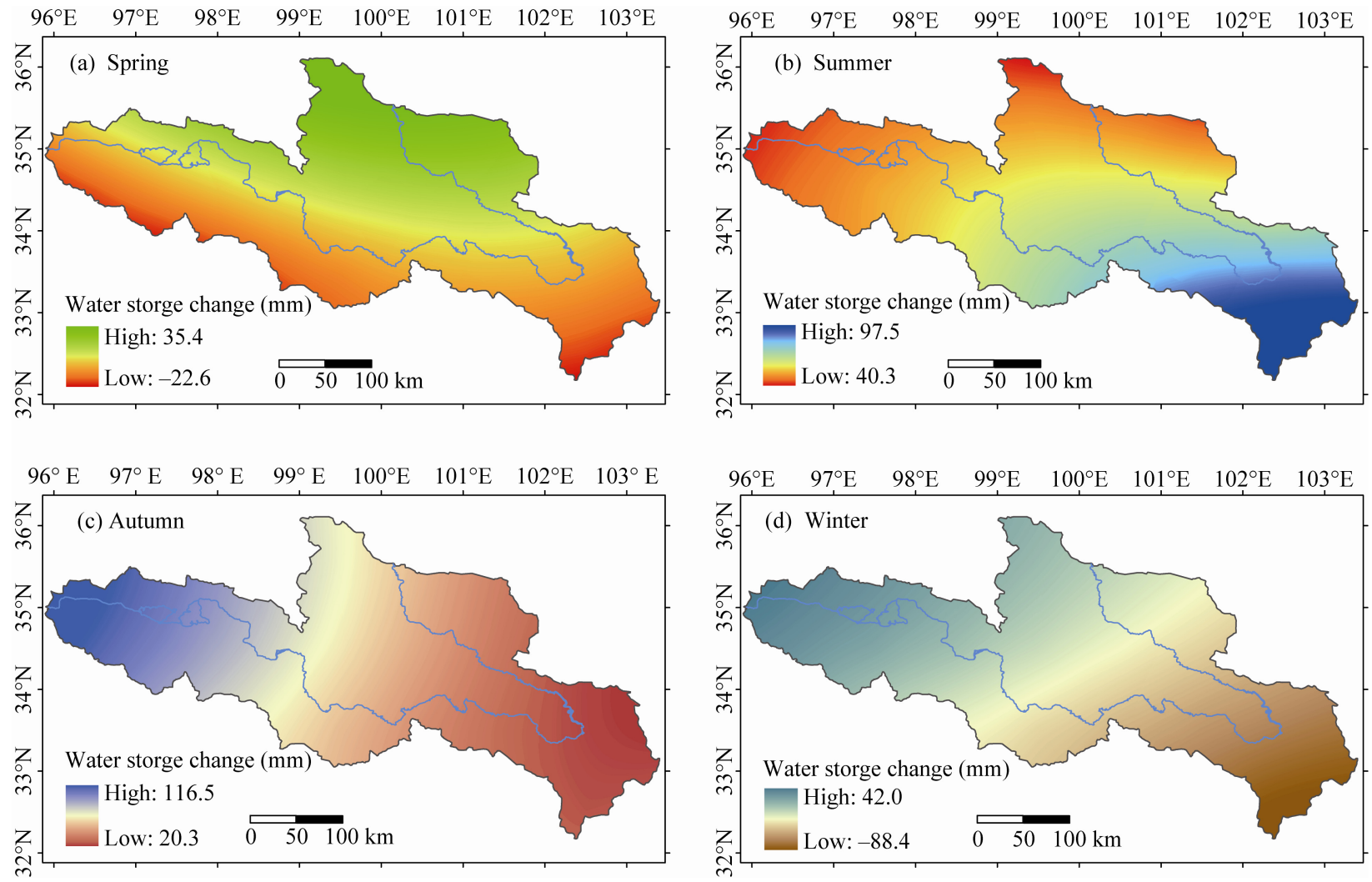

Fig. 3 Seasonal variation of water storage change in the source region of Yellow River basin during 2003-2008 


\subsection{Water balance components change}

Figures $4 \mathrm{a}-\mathrm{d}$ show monthly series and linear trend of water balance components, namely precipitation, runoff, basinal water storage change and the actual evaporation calculated by Eq. 2 . The average annual precipitation in the source region of the Yellow River during 2003-2008 was $637.7 \mathrm{~mm}$. There was no obvious change in inter-annual precipitation, with a minor increase during 2003-2008. Compared with 2003, precipitation decreased by $6.2 \%$ during 2008 , equaling to about $39.7 \mathrm{~mm}$. The average annual runoff was 147.2 $\mathrm{mm}$, with the runoff from the area around Tangnaihai hydrological station having an increase trend at recent years. In 2003 , runoff dropped by $2 \%$ compared with that in 2009, which equates to about $2.8 \mathrm{~mm}$.

The water storage change of the watershed was calculated by Eq. 3 for the period of 2003-2008 from GRACE data. Results showed an increase trend of water storage in the source region of the Yellow River (Fig. 4c) with a rate of $0.51 \mathrm{~mm}$ per month $(P<0.05)$. This may be the reason why precipitation has not ob-
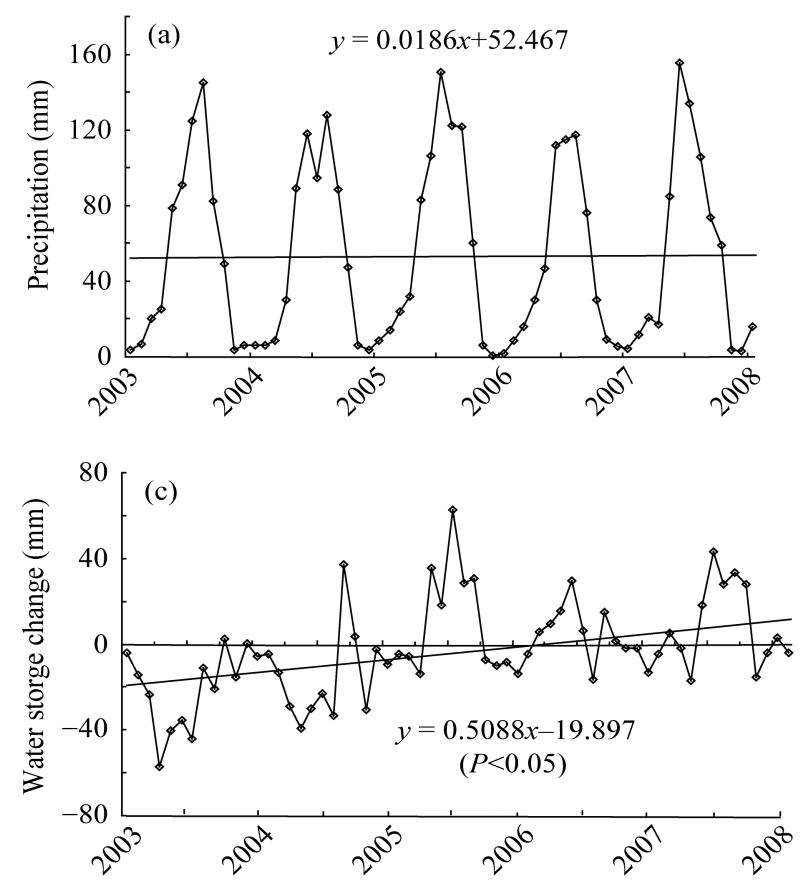

viously increased and runoff has decreased. In addition, climate warming (Fig. 2d) has resulted in degradation of permafrost, which reduced the barrier effect of frozen soil and increased the depth of the activity layer. More surface water seepage into the groundwater within the watershed has caused increasing water storage change. This research result is consistent with that obtained by Niu et al. (2010), which showed that permafrost degradation within the watershed impacts hydrological processes.

According to monthly precipitation, runoff and water storage change, monthly actual evaporation can be calculated using the water balance equation (Fig. 4d; Eq. 2). The monthly average actual evaporation was about $506.4 \mathrm{~mm}$. Results indicated that the actual evaporation showed a decreasing $(P<0.05)$ trend during 2003-2008. It also showed the same results which are obtained based on observation and model calculation (Qiu et al., 2003). These results showed a minimum in 2005 with a value of $403.6 \mathrm{~mm}$ because runoff and water storage changes were more pronounced.
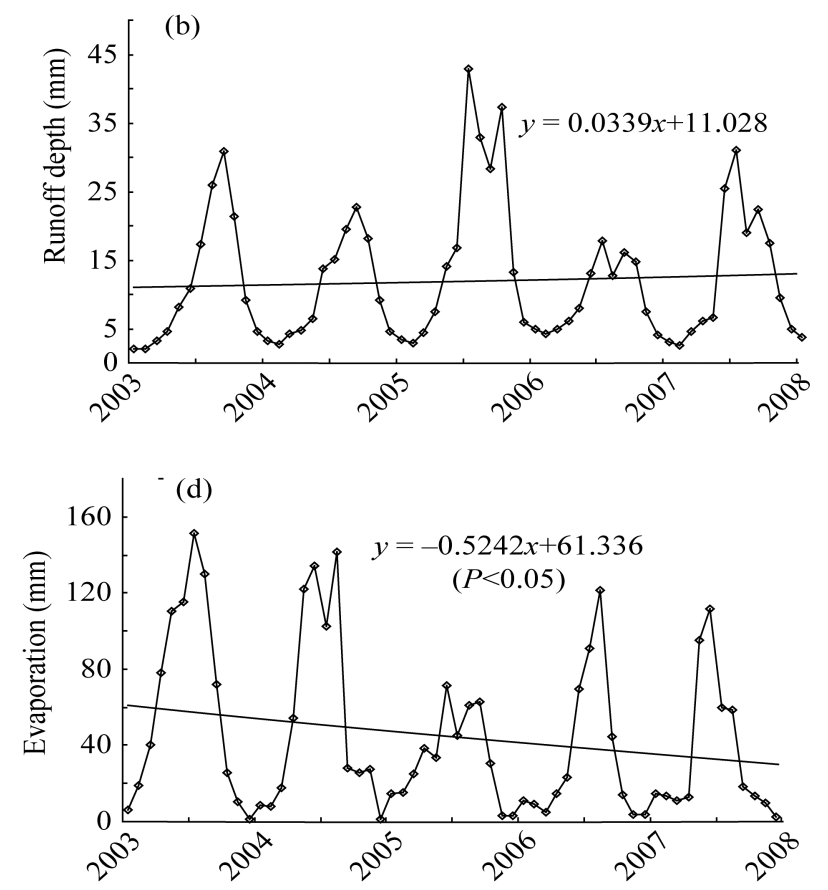

Fig. 4 The monthly time series and linear trend of precipitation (a), runoff depth (b), water storage change (c) and evaporation (d) at the Tangnaihai station of the upper Yellow River basin during the period 2003-2008

\subsection{Monthly distribution of water balance com- ponents}

Average annual precipitation was $637.7 \mathrm{~mm}$ (Fig. 5) and was mainly concentrated during summer and autumn from May to October, accounting for $89 \%$ of the annual total. Precipitation is scarce during winter and 
spring, and most precipitation occurs as solid precipitation from October to April of the next year. The maximum monthly precipitation generally occurs during July, accounting for around $19 \%$ of the annual total; and the minimum monthly precipitation generally occurs during December, accounting for $1 \%$ of the annual total. The monthly maximum and minimum precipitation values show a high degree of variation, indicating that the seasonal distribution of precipitation is extremely uneven.

The average annual runoff was $147.2 \mathrm{~mm}$, being relatively small during January and February, and beginning to show an increase during March and April. Runoff is mainly concentrated in the period from June to October (Table 2), which accounts for $80 \%$ of the total. Runoff gradually begins to decrease during November. The maximum monthly depth of runoff was concentrated during July and October, and the maximum monthly depth has occurred earlier during the year (Table 2). Runoff began to increase from April with the gradually warming weather and the beginning of the snow melting process, thereby starting the surface runoff process. This is consistent with the water storage change increases during summer (Fig. 3).

Average annual actual evaporation calculated was $506.4 \mathrm{~mm}$ using the water balance equation and showed a unimodal distribution on the intra-annual scale. Evaporation was larger from May to September at about $392.8 \mathrm{~mm}$. Evaporation was less during March, April, October and November than during May and September, where evaporation was about $87.5 \mathrm{~mm}$, accounting for $17.3 \%$. Evaporation was 23.9 mm during January and February, which accounted for $4.7 \%$. The minimum value of annual actual evaporation was about $2.2 \mathrm{~mm}$ during December, accounting for about $0.4 \%$ of the yearly total.

The average monthly water storage change was $-15.9 \mathrm{~mm}$ in the source region of the Yellow River. From November to May of the next year, water storage change was in deficit, with the value between $-18.4 \mathrm{~mm}$ and $-6.1 \mathrm{~mm}$. From June to October, water storage change shows a surplus, with the maximum value appearing in September at about $32.4 \mathrm{~mm}$. Water storage change begins to show a "deficit to surplus" trend during June, which is due to the starting of the rainy season during May.

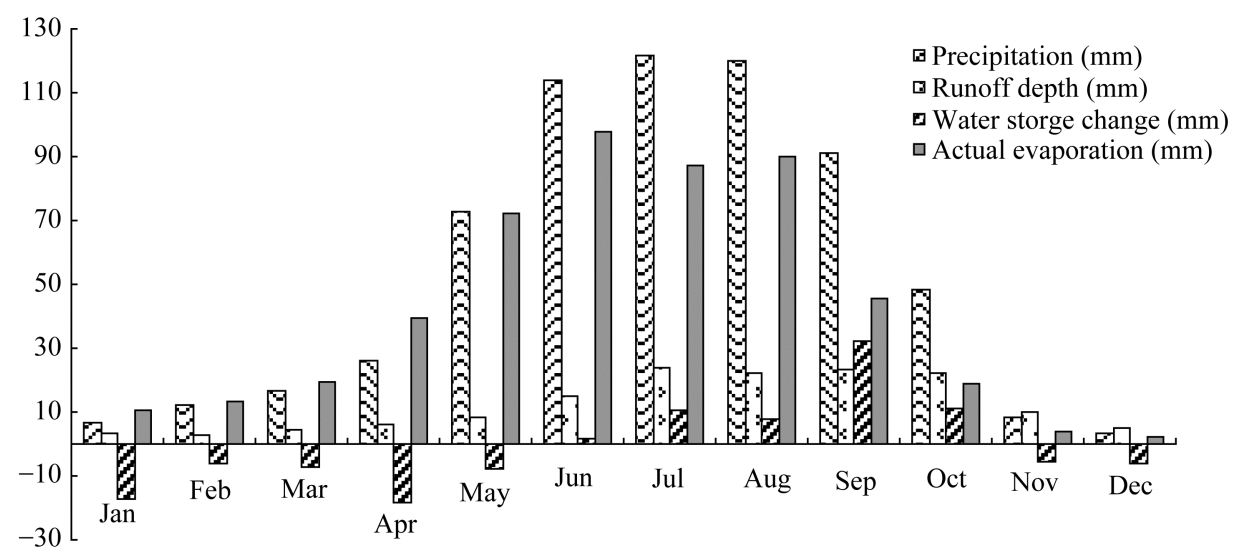

Fig. 5 The monthly variation of precipitation and runoff in the upper Yellow River basin during 2003-2008

Table 2 Peak monthly runoff depth during 2003-2008

\begin{tabular}{ccc}
\hline Year & Maximum runoff depth $(\mathrm{mm})$ & Month \\
\hline 2003 & 30.8 & September \\
2004 & 22.7 & September \\
2005 & 42.8 & July \\
2006 & 17.9 & July \\
2007 & 31.0 & July \\
2008 & 42.8 & July \\
\hline
\end{tabular}

\subsection{Seasonal variation of actual evaporation}

The actual evaporation was calculated using the water balance equation with GRACE data (Table 3). The results show that the actual evaporation declined in spring, summer and autumn during 2003-2008 in the source region of the Yellow River (Fig. 6). Evaporation increased slightly during winter, but did not change drastically. Actual evaporation showed the most obvious decrease trend during spring and sum- 
mer and showed distinctly different values in different seasons. Actual evaporation was $130.9 \mathrm{~mm}$ during spring (March-May), $275.2 \mathrm{~mm}$ during summer (JuneAugust), $74.3 \mathrm{~mm}$ during autumn (September-November) and $26.1 \mathrm{~mm}$ during winter (DecemberFebruary), accounting for $25.8 \%, 54.3 \%, 14.7 \%$ and $5.2 \%$ of the annual total, respectively. The maximum actual evaporation occurred during summer and the minimum occurred during winter. Actual evaporation is higher during spring than in autumn. The actual evaporation in spring and summer accounted for $80.1 \%$ of the annual total.

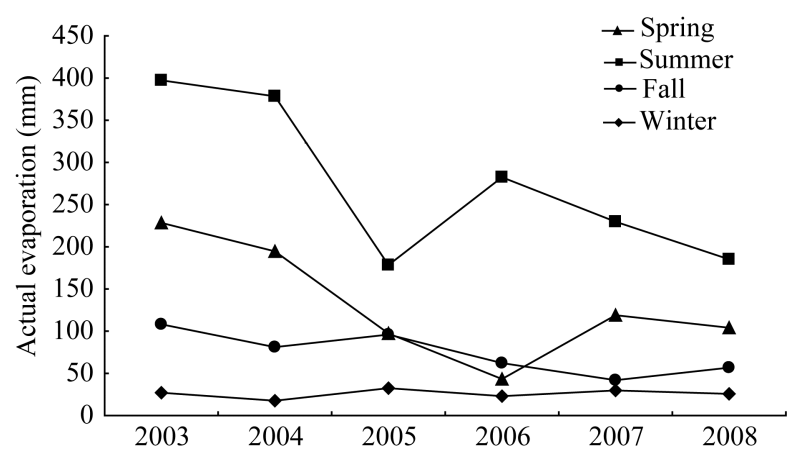

Fig. 6 Variation of seasonal evapotranspiration in the source region of the Yellow River during 2003-2008

\section{Evaporation validation and compari- son}

In this study, evaporation was calculated using three methods: pan interpolation, simulation by the SiB2 model and the water balance equation (Fig. 7). The result of the simulation by the SiB2 model was closer to that of the water balance equation than the observations of pan evaporation. However, there were certain differences between the results of the water balance equation and simulation by SiB2. The trends shown by the three results are consistent. The values observed by pan evaporation are the maximum, and the minimum value was calculated by the water balance equation. Pan evaporation does not represent real evaporation of a watershed because of the different air conditions, dynamics of a watershed and thermodynamics of surface area. Therefore, there are limitations to using pan evaporation measures to estimate evaporation (Qiu et al., 2003; Wang et al., 2006). Many studies show that pan evaporation usually overesti- mates real evaporation, with the conversion coefficient between them usually being 0.4-0.6. Even though evaporation from pan observation was calculated using coefficient correction, it cannot accurately reflect the dynamic change of actual evaporation because the pan conversion coefficient is affected by a variety of factors and seasonal changes (Shi et al., 2003; Ping et al., 2009). The results of the SiB2 model give single point evaporation values, and do not represent actual evaporation on the surface of the whole watershed, but do give actual evaporation. We calculated the average evaporation of seven stations (Table 1, except Jiuzhi) as a reference to the results of the water balance equation, with an aim to verify whether this method is suitable for calculating the actual evaporation of the watershed.

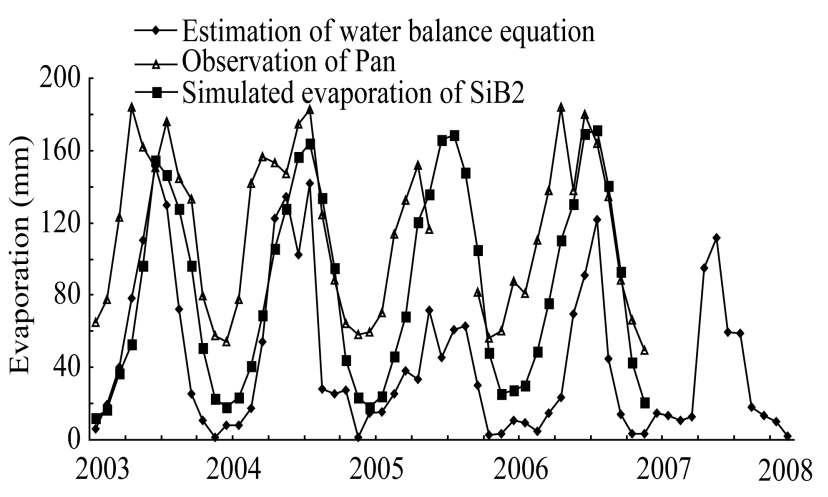

Fig. 7 The monthly evapotranspiration in the upper Yellow River basin above the Tangnaihai station during 2003-2008

The correlation between the observation from pan evaporation and the calculation from the water balance equation was $0.724(P<0.05)$. The correlation between evaporation results of the SiB2 model simulation and calculations of water balance equation was $0.769(P<0.05)$ (Fig. 8). Both the evaporation results of observation from pan evaporation and calculation from the SiB2 model simulation are consistent with the calculation from the water balance equation. However, evaporation which is calculated by the water balance equation is the total evaporation in the watershed as the method follows the rules of the hydrologic cycle. Other methods follow the rules of land surface processes, and they calculate evaporation of single points which cannot represent evaporation of a watershed. 

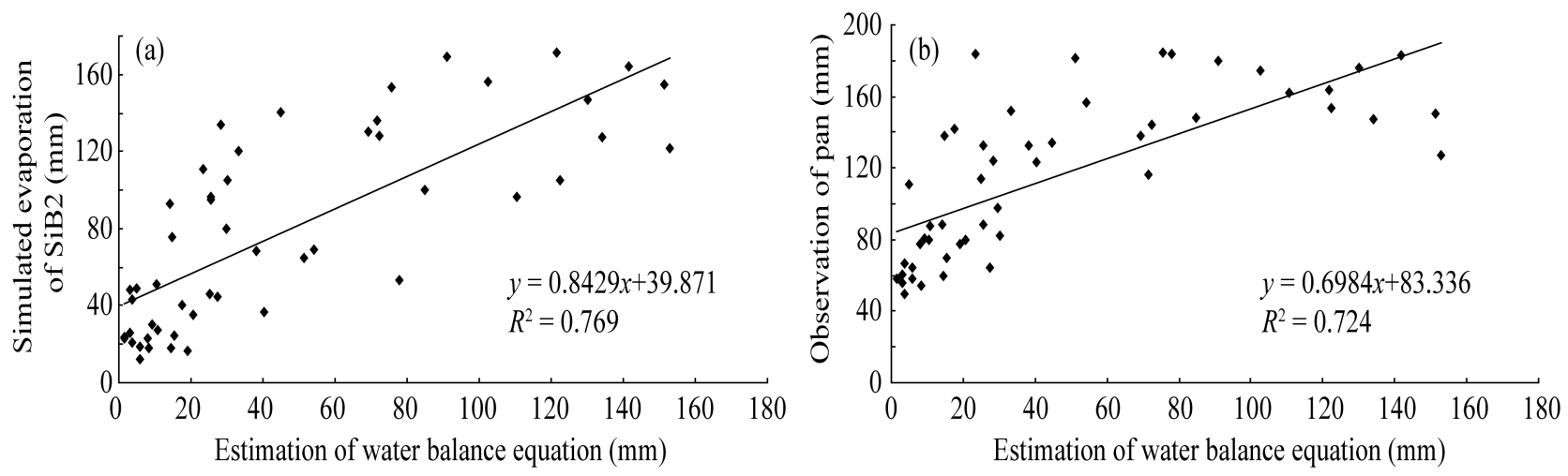

Fig. 8 The relationship between $\mathrm{ET}_{\mathrm{a}}$ and $\mathrm{ET}_{\mathrm{pan}}$ at the Tangnaihai station of the upper Yellow River basin during 2003-2008

\section{Discussion}

Precipitation is the key variable in evaporation calculations; the calculation of precipitation has uncertainties in the watershed. It is well known that there are different methods when interpolating the observed gauge precipitation to the watershed. Four interpolation methods, including Kriging considering elevation, Inverse Distance Weight (IDW), Ordinary Kriging, and Spline were compared in the source region of the Yellow River during 2003 to 2008 (Fig. 9). The results show that four methods do not have large differences in the study area. Thus, we can ignore the error which comes from different interpolation methods of precipitation. However, since the watershed is located in high mountain area, we choose Kriging considered elevation to calculate precipitation in the watershed.

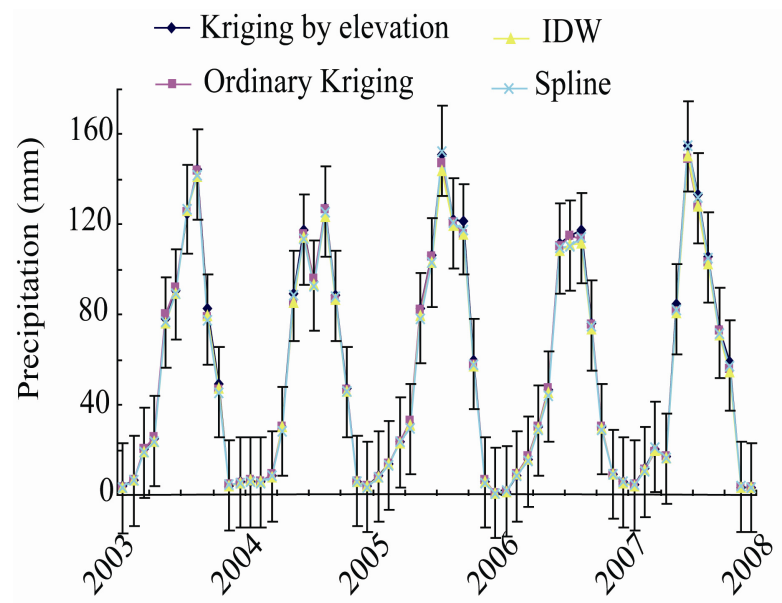

Fig. 9 Precipitation by different methods in the source region of the Yellow River during 2003-2008

It is necessary to document and discuss the accu- racy of water balance results for regional and basin studies (Ye et al., 2012). In this study, water equivalent changes from GRACE solutions up to degree and order 60 were used to calculate water storage changes. The source region of the Yellow River contains an appreciable extent of permafrost. Permafrost plays a major role in the drainage characteristics of the study area. The near-surface soil-earth layer that seasonally freezes and thaws (the active layer) is another factor in permafrost watersheds (Yoshikawa and Hinzman, 2003). Changes in the active layer affect soil moisture and groundwater. Dynamics of permafrost and the active layer exert significant influences on surface and groundwater hydrology (Yoshikawa et al., 2006; Oberman et al., 2008; Muskett et al., 2011). Therefore, the GRACE monthly water equivalent changes captured the changes of base flow from groundwater storage changes, and surface water changes in the permafrost watershed of the Yellow River. In related research, GRACE-derived water storage change is increasing in the Lena and Yenisei River watershed regions of Eurasia (Muskett et al., 2009). These watersheds encompass large areas of the continuous and discontinuous permafrost zones and talik (a layer of year-round unfrozen ground).

The actual evaporation of a watershed is difficult to estimate in high accuracy. Generally, single points of evaporation are obtained by simulation or interpolated by observation of pan evaporation. However, these single points cannot represent actual evaporation of a whole watershed. Water storage change is a critical parameter in the water balance equation. If water storage change data of high accuracy can be obtained, it is simple to calculate actual evaporation using the 
water balance equation. In this study, the water storage change during 2003-2008 in the source region of the Yellow River was retrieved from GRACE satellite data. By combining these data with precipitation and runoff data, the actual evaporation of the whole watershed was calculated. The results were compared with the simulations of the SiB2 model and the results obtained by interpolation of pan evaporation observations. These data showed the same trends and consistent and good correlative relationships. This is a new method based on the water balance equation for calculating actual evaporation of a watershed.

\section{Conclusions}

This research introduced a new method based on the water balance equation to calculate actual evaporation using water storage change which is retrieved from GRACE satellite data. The water balance components (precipitation, runoff, water storage change and actual evaporation) were studied in the source region of the Yellow River. The results show that the water balance equation was used to calculate actual evaporation considering the basin water storage changes. The annual average actual evaporation was $506.4 \mathrm{~mm}$ in the study area. The trend of actual evaporation showed a decline during the period of 2003-2008. The evaporation calculated by the water balance equation are consistent with the evaporation given by pan observations and the evaporation simulated by the $\mathrm{SiB} 2$ model with the correlation coefficients of 0.724 and 0.769 , respectively. The trend of water storage change showed an increase during the period of 2003-2008 in the source region of the Yellow River with a rate of $0.51 \mathrm{~mm}$ per month. One reason is the increased precipitation while another is the permafrost degradation in the watershed due to climate warming. As the role of frozen groundwater reduces, the increasing water storage leads to the increase in the underground reservoir capacity. More surface water infiltration into the groundwater in the basin causes the increases in the groundwater reservoir. Actual evaporation declined for a period of nearly 6 years in the source region of the Yellow River. Annual evaporation decreased during spring, summer and autumn, while it changed little during winter. Actual evaporation showed an obvious decline during spring and autumn, being concentrated in May-September and accounting for $77.6 \%$ of the annual total. In the case of little precipitation, the decrease of evaporation and the increase of water storage change is a significant and common cause of increased surface runoff.

\section{Acknowledgments}

This work was funded by the Global Change Research Program of China (2010CB951401), the National Natural Science Foundation of China (41030638, 41121001, 41030527, 41130641, and 41201025) and the One Hundred Talents Program of the Chinese Academy of Sciences. We thank NASA for making data available at http://grace.jpl.nasa.gov.

\section{References}

Byron D T, Srinivas B, John C R, et al. 2004. GRACE measurements of mass variability in the earth system. Science, 23: 305-503.

Ding Y J, Yang D Q, Ye B S, et al. 2007. Effects of bias correction on precipitation trend over China. Journal of Geophysical Research, 112 D13116.

Döll P, Kaspar F, Lehner B. 2003. A global hydrological model for driving water availability indicators: model tuning and validation. Journal of Hydrology, 70: 105-134.

$\mathrm{Hu}$ X G, Chen J, Zhou Y, et al. 2006. GRACE space gravity measurements to monitor the use of the Yangtze River seasonal changes in water storage. Science in China: Earth Science, 36(3): 225-232.

Kinfu H H. 2011. Estimation of terrestrial water storage in the upper reach of Yellow River. Msc. Thesis. Nederland: University of Twente, 7-11.

Milly P C D, Shmakin A B. 2002. Global modeling of land water and energy balances. Part I: the land dynamics (LaD) model. Journal of Hydrometeorology, 3: 283-299.

Muskett R R, Romanovsky V E. 2009. Groundwater storage changes in arctic permafrost watersheds from GRACE and in situ measurements. Environmental Research Letters, 4: 045009.

Muskett R R, Romanovsky V E. 2011. Alaskan permafrost groundwater storage changes derived from GRACE and ground measurements. Remote Sensing, 3: 378-397.

Niu L, Ye B S, Li J, et al. 2010. Effect of permafrost degradation on hydrological processes in typical basins with varying permafrost coverage in Western China. Science in China: Earth Science, 53: $1-10$.

Oberman N G. 2008. Contemporary permafrost degradation of northern European Russia. In: Kane D L, Hinkel K M. Proceedings of $9^{\text {th }}$ International Conference on Permafrost, University of Alaska Fairbanks, 29 June-2 July: 1305-1310.

Ohmura A, Wild M. 2002. Is the hydrological cycle accelerating? Sci- 
ence, 298: 1345-1346.

Qiu X, Liu C H, Zeng Y. 2003. Changes of pan evaporation in the recent 40 years over the Yellow River Basin. Journal of Natural Resource, 18: $437-442$.

Ramillien, Cazenave A, Brunau O. 2004. Global time variations of hydrological signals from GRACE satellite gravimetry. Geophysical Journal International, 158: 813-826.

Rodell M, Houser P R, Jambor U, et a1. 2004. The global land data assimilation system. Bulletin of the American Meteorological Society, 85(3): 381-394.

Shi C X, Niu K Y, Chen T Z, et al. 1986. The study of pan coefficients of evaporation pans of water. Scientia Geogrophica Sinica, 6(4): 305-313.

Tapley B D, Bettadpur S, Ries J C, et al. 2004a. GRACE measurements of mass variability in the Earth system. Science, 305: 503-505.

Tapley B D, Bettadpur S, Watkins M, et al. 2004b. The gravity recovery and climate experiment: mission overview and early results. Geophysical Research Letters, 31: L09607.

Velicogna I, Wahr J. 2006. Measurements of time-variable gravity show mass loss in Antarctica. Science, 311: 1745-1756.

Wahr J, Swenson S. 1998. Time variability of the earth gravity field: hydrological and oceanic effects and their possible detection using GRACE. Journal of Geophysical Research, 103(12): 30205-30229.

Wahr J, Swenson S, Zlotnicki V, et al. 2004. Time-variable gravity from GRACE: first results. Journal of Geophysical Research, 31: L11501.

Wang Y J, Jiang T, Xu C Y, et al. 2005. Trends of evapotranspiration in the Yangtze river basin in 1961-2000. Advances in Climate Change Research, (3): 99-105.

Wang Y J, Jiang T, Xu C Y. 2006. Spatial-temporal change of $20 \mathrm{~cm}$ pan evaporation over the Yangtze River basin. Advances in Water Science, 17(6): 830-833.

Wang Y J, Jiang T, Liu B. 2010. Trends of estimated and simulated actual evaporation in the Yangtze river basin. Acta Geographic Sinica, 65(9): 1079-1088.

Wu X N, Hu T S, Wang X G, et al. 2006. Review of estimating and measuring regional evaporation. Transactions of the CSAE, 22(10):
257-262.

Xie P, Chen X H, Wang Z L. 2009. Comparison of actual evaporation and pan evaporation. Acta Geographic Sinica, 64(3): 270-277.

Xu M, Wang Y, Zhou Z Y, et al. 2012. Discussion of methods on spatial interpolation for monthly temperature data in Yangtze River basin. Resources and Environment in the Yangtze Basin, 21(3): 327-334.

Yang K, Chen Y Y, Qin J. 2009. Some practical notes on the land surface modeling in the Tibetan Plateau. Hydrology and Earth System Sciences, 13: 687-701.

Yang K, Ye B, Zhou D, et al. 2011. Response of hydrological cycle to recent climate changes in the Tibetan Plateau. Climatic Change, 109: 519-534

Yang Y D, E D C, Chao D B, et a1. 2009. Seasonal and inter-annual change in land water storage from GRACE. Chinese Journal Geophysics, 52(12): 2987-299.

Yang Z N, Hu M G, Liu X R, et al. 1996. Alpine permafrost zone water balance and runoff characteristics. Science in China: Earth Science, 26(6): 567-573.

Ye B S, Yang D Q, Ding Y J, et al. 2007. A Bias-corrected precipitation climatology for China. Acta Geographic Sinica, 2007, 62(1): 3-13.

Ye B S, Yang D Q, Ma L Q. 2012. Effect of precipitation bias correction on water budget calculation in upper Yellow River, China. Environmental Research Letters, doi: 10.1088/1748-9326/7/2/025201.

Yoshikawa K, Hinzman L D. 2003. Shrinking thermokarst ponds and groundwater dynamics in discontinuous permafrost near council, Alaska. Permafrost and Periglacial Process, 14: 151-160.

Yoshikawa K, Romanovsky V, Hinzman L, et al. 2006. Intra-permafrost water and hydrological chronology: a case study of aufeis and spring hydrology in continuous permafrost regions. EOS Transactions AGU Fall Meeting: U31B-07.

Zenner L, Gruber T, Jäggi A, et al. 2010. Propagation of atmospheric model errors to gravity potential harmonics-impact on GRACE de-aliasing. Geophysical Journal International, 182: 797-807.

Zhong M, Duan J B, Xu H Z, et al. 2009. Trend of China land water storage redistribution at medi- and large-spatial scales in recent five years by satellite gravity observations. Chinese Science Bulletin, 54(5): 816-821. 